\title{
FOREIGN BOOK.
}

Diagnostile der Nertenkrankheiten. Von Prof. Dr. Alexander MarGulies. Erster Band. Allgemeiner Pathologischer Teil. Ss. 120. Mit 13 Abbildungen. Berlin: S. Karger. 1914. Preis $3 \mathrm{M}$.

In this little book the author gives a brief sketch of the leading symptoms and signs met with in diseases of the nervous system. The disturbances of movement, sensation, and of the reflexes, the diseases of the brain, cerebellum, cranial nerves, spinal cord and sympathetic system, the examination of the cerebro-spinal fluid and disturbances of the internal secretions and their influence on the nervous system are discussed in successive chapters.

\section{NOTES ON BOOKS.}

Most clinicians who have fairly tried radiography in the diagnosis of pulmonary disease will agree that it gives information of great value, and in many cases detects lesions which would otherwise escape notice by the usual methods. As we believe that radiography deserves to be more widely used, we welcome Dr. Cooke's book on The Position of the X-Rays on the Liagnosis and Prognosis of Pulmonary Tuberculosis (Gilmour \& Lawrence, Ltd., Glasgow) as a short, clear guide to the subject.

As usual, The Practical Medicine Series of Digests is excellent. Volume I., on "General Medicine" (Chicago: The Year-Book Publishers), for 1914, is now before us. The editors' names-Frank Billings, M.D., and J. H. Salisbury, M.D.-are guarantee of its quality. We may remind our readers that ten volumes of this series, covering the various departments of medicine and surgery, are issued annually at the price of 10 dollars, but that each volume is purchasable separately.

Tomes' Dental Anatomy (J. \& A. Churchill, price 15s. net) has been so long and favourably known to successive generations of students of human and comparative odontology that it is scarcely necessary to do more than accord a welcome to the seventh edition, in the production of which Drs. Marett Tims and Hopewell Smith have collaborated with the author. The book has been rearranged in accordance with modern views and much new matter has been added, bringing it thoroughly up to date. Particularly noticeable are the sections on the development of the human jaws and on the teeth of prehistoric man. Owing to the practical importance of the subject to the dental student, we would suggest that in the next edition the chapter upon the teeth of man should be considerably extended. Although still marred by a number of misprints, the book has been greatly improved by increasing the size of the page and enlarging the type. It still remains the best of its kind in the English linguage. 